\title{
Alcoholic liver disease in Nepal: identifying homemade alcohol as a culprit
}

This article was published in the following Dove Press journal:

Clinical and Experimental Gastroenterology

13 July 2015

Number of times this article has been viewed

\section{Bickram Pradhan' \\ Antoine Hadengue ${ }^{2}$ \\ François Chappuis ${ }^{3}$ \\ Shatdal Chaudhary' \\ Dharanidhar Baral ${ }^{4}$ \\ Pascal Gache ${ }^{5}$ \\ Prahlad Karki ${ }^{6}$ \\ Suman Rijal ${ }^{6}$}

'Division of Gastroenterology and Hepatology, Department of Internal Medicine, B P Koirala Institute of Health Sciences, Dharan, Nepal; ${ }^{2}$ Department of Gastroenterology and Hepatology, ${ }^{3}$ Division of Tropical and Humanitarian Medicine, Geneva University Hospital, Geneva, Switzerland; ${ }^{4}$ Department of Community Medicine and School of Public Health, B P Koirala Institute of Health Sciences, Dharan, Nepal; ${ }^{5}$ Department of Health and Community Medicine. Geneva University Hospital, Geneva, Switzerland; ${ }^{6}$ Department of Interna Medicine, B P Koirala Institute of Health Sciences, Dharan, Nepal
Correspondence: Bickram Pradhan Department of Internal Medicine, B P Koirala Institute of Health Sciences, Dharan, Sunsari, Nepal

Tel +9779842060202

Fax +97725 52025 I

Email bickram.p@gmail.com
Background: Though the type of alcohol consumed is not thought to be associated with alcoholic liver disease (ALD), some studies have shown a beverage-specific effect. In the present study, we aim to study the effects of locally brewed alcoholic beverages on the development of liver disease.

Patients and methods: This cross-sectional study was conducted at the internal medicine department of a university hospital in Nepal. All patients classified as having either alcohol abuse or alcohol dependence by the Diagnostic and Statistical Manual of Mental Disorders, 4th Edition were evaluated for the presence of ALD.

Results: A total of 1,500 patients were screened, of which, 447 patients had ALD. Chronic liver disease (CLD) was detected in 144 patients (9.6\%). Most of the patients consumed homemade locally brewed alcohol. On multivariate analysis, the following variables were found to be significantly associated with CLD: male sex (odds ratio [OR]: $1.81 ; 95 \%$ confidence interval [CI]: 1.12-2.94; $P=0.02$ ): rakshi consumption $\geq 30$ units (OR: $2.53 ; 95 \%$ CI: $1.07-6.01 ; P=0.04$ ); and tongba consumption (OR: $3.02 ; 95 \% \mathrm{CI}: 1.22-7.50 ; P=0.02$ ).

Conclusion: There was a significant increase in the risk of developing ALD with the consumption of rakshi and tongba after adjusting for total units consumed. The absence of striking differences between our patients with CLD and non-CLD patients with regards to the amount of alcohol consumed demonstrates that, although alcohol consumption is a prerequisite for the development of ALD, other factors like type of alcoholic beverage consumed may be involved.

Keywords: alcohol use disorders, alcoholic liver disease, locally brewed alcohol

\section{Introduction}

Heavy drinking is associated with the development of liver cirrhosis. The relationship between the quantity of alcohol ingested and the development of liver disease is not clearly linear. ${ }^{1,2}$ However, the risk of developing cirrhosis increases with the ingestion of $\geq 60-80 \mathrm{~g} /$ day of alcohol for 10 years or longer in men and $\geq 20 \mathrm{~g} /$ day in women; 3,4 yet, even drinking at these levels, only $6 \%-41 \%$ develop cirrhosis. ${ }^{3,5}$ In a populationbased cohort study of almost 7,000 subjects in two northern Italian communities, even among patients with very high daily alcohol intake ( $\geq 120 \mathrm{~g} /$ day), only $13.5 \%$ developed alcoholic liver disease (ALD). ${ }^{4}$ Although there is a well-known relationship between total alcohol intake and future risk for cirrhosis, other factors such as the type of alcohol consumed are sparsely studied. A prospective epidemiological study performed in Denmark concluded that, for a given daily dose of pure alcohol, the risk of cirrhosis was significantly decreased when wine accounted for $30 \%-50 \%$ of the total dose ${ }^{6}$ a similar, although not significant, trend was found in a study from the United States. ${ }^{7}$ 
Regarding the consumption of alcohol, Nepal is a unique country. Alcohol is consumed in various forms. Types of traditional and local alcoholic beverages include country liquors (low-quality alcohol made from molasses and produced in small distilleries), homemade liquors, jad (made of rice), chhang (made of rice by a different method), and rakshi (homebrewed alcohol made out of rice, millet, or barley). While it is the ethanol in spirits that is primarily responsible for liver damage, other aliphatic alcohols have even more pronounced hepatotoxic effects. ${ }^{8,9}$ Consequently, it is important to know whether the large volume of homemade spirits consumed in this region pose an additional risk factor for the development of alcohol-induced cirrhosis. Despite the high prevalence of alcohol misuse and the easy availability of different types of alcoholic beverages, there are no studies on the prevalence of ALD. In addition, the effect of the type of alcohol consumed and drinking patterns are unknown in this setting. In the present study, the aim was to detect the prevalence of ALD in patients attending a large internal medicine outpatient clinic, and to delineate the type of alcohol consumed, as well as the drinking patterns and the risk of ALD.

\section{Patients and methods}

This cross-sectional study was conducted for 6 months (from March 15, 2009 to September 15, 2009) in the Internal Medicine Department of the B P Koirala Institute of Health Sciences (BPKIHS) (Dharan, Nepal), a university hospital serving the peoples of eastern Nepal.

\section{Subjects}

Patients attending the outpatient service of the Internal Medicine and Gastroenterology and Hepatology clinics in stable medical condition were enrolled in the study. Every fifth patient of the total new patients registered was enrolled in the study. Patients admitted to the coronary care or intensive care units, or who were too ill or confused to be interviewed, were excluded. Patients previously diagnosed with ALD and patients refusing to sign the informed consent paper were also excluded from the study. All patients provided informed written consent and the study was approved by the institutional ethical review board.

\section{Screening for alcohol misuse: questionnaires and interviews}

The medical personnel and two research nurses were trained for 7 days before the beginning of the study in order to be able to administer the questionnaires uniformly. The alco- hol section of the Structured Clinical Interview Diagnosis (SCID) for the Diagnostic and Statistical Manual of Mental Disorders, Fourth Edition (DSM-IV), which is a semistructured questionnaire, was used as a reference standard (gold standard) for alcohol dependence and alcohol abuse. The SCID for DSM-IV Axis I Disorders (SCID-I) is a semistructured interview for making the major DSM-IV Axis I diagnoses. ${ }^{10}$ Patients were interviewed about alcohol issues using the alcohol section of the SCID for the DSM-IV. Finally, patients were classified into one of three categories: no alcohol problem (abstinent or low-risk drinker); alcohol abuse; or alcohol dependence.

For alcohol intake, a colored illustrated picture of the glass or vessel commonly used to consume alcoholic beverages was used in all cases to quantify alcohol use. The participants were asked about their daily intake of different types of alcoholic beverages in a typical week. These were added up to yield the weekly intake. Then, the following questions were asked: "Are there any days where you drunk more?"; "Would you say that last week is representative of the last 12 months?"; and "If no, can you explain to me in which sense?" Total units drunk per week were calculated adjusting for the extra drink. The duration of alcohol misuse, defined as years since the onset of alcohol misuse at the time of the interview, was recorded. The predominant type of alcohol consumed within the last month was recorded with five possibilities: rakshi; chhang; tongba; sprits; or beer or mixed type of alcohol. A standard drink contains $10 \mathrm{~g}$ of alcohol. Binge drinking was defined as the intake of $\geq 5$ drinks for males and $\geq 4$ drinks for females within a 2-hour period. Particular attention was devoted to quantify locally brewed beverages. Thus, several samples of locally brewed alcohols were analyzed for their alcohol concentration in the laboratory of the Hôpitaux Universitaires de Genève (Geneva University Hospitals, Geneva, Switzerland) and the following results were obtained: rakshi, 25\%; chhang, $12 \%$; and tongba, $5.5 \%$.

\section{Screening for liver disease}

All patients that were classified as having either alcohol abuse or alcohol dependence by the nurse were examined by two investigators from BPKIHS for the presence of clinical signs of liver disease; blood samples were taken by the nurse on the same day. A detailed physical examination was performed to detect the signs of liver disease, such as the presence of jaundice, spider naevi, palmer erythema, abdominal collaterals, a palpable firm liver, and ascites. Blood samples were collected to check for serum bilirubin, serum alanine aminotransferase, serum aspartate aminotransferase, $\gamma$-glutamyl transferase, 
prothrombin time, mean cell volume, and platelet count. Each patient who had two abnormal blood tests or physical signs suggestive of liver damage were classified as having suspected liver disease, and further work up of these patients was carried out to confirm the presence of liver disease. The following additional investigations were performed in these groups of patients: 1) other liver function tests like serum alkaline phosphatase, serum total protein, serum albumin, serum globulin, blood assay of hemoglobin, total white blood cell count, blood glucose, serum ferritin, and total iron binding capacity; moreover, the presence of hepatitis B and hepatitis $\mathrm{C}$ were detected by determining the presence of the surface antigen for hepatitis B virus (HBsAg) and antihepatitis $\mathrm{C}$ virus in the serum; 2) ultrasonography of the liver, biliary system, pancreas, and spleen, with measurement of the portal vein diameter, as well as a Doppler study of the portal vein and hepatic venous blood flow; and 3) other diagnostic procedures, such as percutaneous liver biopsy, were performed if indicated.

Diagnosis of ALD was based on a history of significant alcohol consumption, physical signs of liver disease, biochemical parameters, imaging studies, ${ }^{11,12}$ and liver biopsy in selected cases. Liver biopsy was performed according to the indications for liver biopsy. ${ }^{13}$

\section{Classification of liver disease}

Patients were classified into one of two groups: chronic liver disease (CLD); or no detectable liver disease, according to the presence of cirrhosis at liver biopsy or to the presence of the following criteria: ${ }^{4}$

1. spider nevi, jaundice, palmar erythema, ascites, flapping tremor, spleen enlargement;

2. platelet count $<140,000 / \mathrm{mm}^{3}$;

3. portal vein diameter $>12 \mathrm{~mm}$ or irregular margins of the liver parenchyma at ultrasonography; and

4. esophageal or fundal varices at upper gastrointestinal endoscopy.

Two clinicians, the principal investigator (BP) and one hepatologist from HUG (AH) independently assigned patients to the two categories. In case of disagreement, the files of the patients were reviewed in a common meeting before reaching a conclusion.

\section{Statistical analysis}

The demographic and clinical characteristics of patients with and without CLD were compared using Pearson's chi-squared test for categorical data or Student's $t$-test for continuous variables. Logistic regression was performed to assess the impact of clinical and sociobehavioral variables on the likelihood of having CLD in this particular population of alcohol abusers. A backward stepwise procedure was used to select the independent predictors and confounders using $P<0.25$ at entry and $P<0.005$ to keep the variables in the model. The variable age was forced into the model, as it is a well-known confounder of ALD. ${ }^{14,15}$ The type of alcohol was assessed as an independent predictor of CLD. For rakshi and chhang, we created a categorical variable based on the quartiles of distribution ( $<5$ units, 5-13 units, 13-30 units, and $\geq 30$ units of ethanol; and $<5$ units, 5-15 units, 15-30 units, and $\geq 30$ units of ethanol, respectively). For tongba, we created a dichotomous variable due to the narrower distribution of units of ethanol linked with tongba ( $<3$ units and $\geq 3$ units of ethanol). Finally, in order to assess the independent variables, we created one variable assessing the association with complementary units of ethanol found in other types of alcohol (beer, wine, and whisky) by using the following cutoffs: $<5$ units of ethanol per day; 5-10 units of ethanol per day; and $\geq 10$ units of ethanol per day. Goodness of fit was assessed using the HosmerLemeshow test. The predictive value of the multivariate model was defined with the area under the curve and its 95\% confidence interval (CI). Data were analyzed using Stata IC10 (StataCorp LP, College Station, TX, USA). All $P$-values were two-sided and the level of significance was set at $P<0.05$.

\section{Results}

Among the 1,500 patients screened, 447 patients were included (Figure 1). Their demographic and clinical characteristics are presented in Table 1. Among the patients studied, 144 (108 males; 36 females) had CLD. The majority of patients in the CLD group were in Child-Turcotte-Pugh (CTP) A (number [n] =69), followed by CTP B $(n=48)$, and CTP C ( $n=27)$.

Data concerning detailed alcohol consumption are also presented in Table 1 . The mean \pm standard deviation units of alcohol consumed per day was higher in the CLD group (23.8 \pm 19.8$)$ than in the non-CLD group (19.9 \pm 21.2$)$; this increase pertained to all types of alcoholic beverages examined. However, these differences did not reach statistical significance $(P=0.06)$. Most of the patients consumed homemade, locally brewed alcohol, like chhang $(62 \%)$, rakshi (77\%), and tongba (16.3\%). Very few patients consumed commercially available spirits $(2.5 \%)$ or wine $(12.3 \%)$. Though most of the patients were mixed drinkers, 95 were excusive rakshi drinkers and 50 were exclusive chhang drinkers. 
Total number of individuals screened, $n=1,500$

Individuals who never drank alcohol, $\mathrm{n}=312$

Individuals assessed for the presence of alcohol abuse/dependence, $n=1,188$

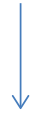

Total number of alcohol abusers/alcohol dependence, $n=479$

Patients excluded, $n=32$ : four patients were very sick, nine patients did not give consent,

15 patients withdrew after initial approval, four incomplete files

Total number of patients assessed for presence of ALD, $n=447$

Figure I Flow chart for the section of the study population.

Abbreviations: $n$, number; ALD, alcoholic liver disease.

Several predictors of CLD were assessed in Table 2 using univariate logistic regression analysis. The following variables were found to be significantly associated with CLD: male sex (odds ratio [OR]: 1.94; 95\% CI: 1.25-3.02; $P=0.003$ ); rakshi consumption of $13-30$ units (OR: 1.81 ; $95 \%$ CI: $1.08-3.04 ; P=0.03)$ and $\geq 30$ units (OR: $2.99 ; 95 \% \mathrm{CI}$ : 1.37-6.52; $P=0.0006$ ); and tongba consumption (OR: 2.91 ; 95\% CI: $1.24-6.80 ; P=0.01)$.

On multivariate analysis (Table 3 ), the following variables were found to be significantly associated with CLD: male sex (OR: $1.81 ; 95 \%$ CI: $1.12-2.94 ; P=0.02)$; rakshi consumption $\geq 30$ units (OR: 2.53 ; 95\% CI: $1.07-6.01$; $P=0.04$ ); and tongba consumption (OR: $3.02 ; 95 \% \mathrm{CI}$ : $1.22-7.50 ; P=0.02)$.

\section{Discussion}

This study shows that among patients with alcohol use disorders (either abuse or dependence), ALD was present in $32.2 \%$. In our study, we found that most of our patients drank locally-made alcoholic beverages. Furthermore, careful eval-

Table I Demographic and clinical characteristics of the study population

\begin{tabular}{|c|c|c|c|c|}
\hline Variables & $\begin{array}{l}\text { Chronic liver disease } \\
(n=\mid 44)\end{array}$ & $\begin{array}{l}\text { No liver disease } \\
(n=303)\end{array}$ & $\begin{array}{l}\text { Total } \\
(n=447)\end{array}$ & $P$-value \\
\hline Sex, n (\%) & & & & 0.003 \\
\hline Males & $108(75.0)$ & $184(60.7)$ & $292(65.3)$ & \\
\hline Females & $36(25.0)$ & $119(39.3)$ & $155(34.7)$ & \\
\hline Mean age in years (SD) & $54.0( \pm 10.9)$ & $53.2( \pm 13.7)$ & $53.5( \pm 12.9)$ & 0.55 \\
\hline Smokers, n (\%) & $96(66.7)$ & $218(71.9)$ & $314(70.3)$ & 0.25 \\
\hline Mean packs per year (SD) & $16.5( \pm 16.4)$ & $16.6( \pm 20.1)$ & $16.6( \pm 19.0)$ & 0.97 \\
\hline Mean BMI (SD) & $22.7( \pm 3.4)$ & $22.0( \pm 3.9)$ & $22.2( \pm 3.8)$ & 0.04 \\
\hline Alcohol dependence, n (\%) & & & & $<0.001$ \\
\hline No & $12(8.3)$ & $72(23.8)$ & $84(18.8)$ & \\
\hline Yes & I 32 (9|.7) & $23 \mid(76.2)$ & $363(8 \mid .2)$ & \\
\hline Mean units of alcohol per day (SD) & $23.8( \pm 19.8)$ & $19.9( \pm 21.1)$ & $21.1( \pm 20.8)$ & 0.06 \\
\hline \multicolumn{5}{|l|}{ Types of alcohol consumed*, n (\%) } \\
\hline Rakshi & $107(74.3)$ & $237(78.2)$ & $344(77.0)$ & 0.36 \\
\hline Chhang & $77(53.5)$ & $200(66.0)$ & $277(62.0)$ & 0.01 \\
\hline Tongba & $28(19.4)$ & $45(14.9)$ & $73(16.3)$ & 0.22 \\
\hline Beer & $30(20.8)$ & $50(16.9)$ & $80(17.9)$ & 0.26 \\
\hline Wine & $20(13.9)$ & $35(11.6)$ & $55(12.3)$ & 0.75 \\
\hline Whisky & $4(2.8)$ & $7(2.3)$ & II (2.5) & 0.48 \\
\hline Mean age at first alcohol use (SD) & $17.3( \pm 7.8)$ & $16.5( \pm 7.8)$ & & 0.30 \\
\hline Mean age of start of alcohol abuse or dependency (SD) & $21.6( \pm 8.4)$ & $20.9( \pm 7.7)$ & & 0.43 \\
\hline Mean time of alcohol intake in years (SD) & $32.5( \pm \mid 4.2)$ & $32.0( \pm 15.1)$ & $32.2( \pm \mid 4.8)$ & 0.75 \\
\hline
\end{tabular}

Note: *Proportion of each type of alcohol consumption among patients with and without chronic liver disease.

Abbreviations: $\mathrm{n}$, number; SD, standard deviation; BMI, body mass index. 
Table 2 Factors associated with the likelihood of having chronic liver disease (univariate analysis)

\begin{tabular}{|c|c|c|c|}
\hline Variables & OR & $95 \% \mathrm{Cl}$ & $P$-value \\
\hline Sex & & & 0.003 \\
\hline Females & 1.00 & & \\
\hline Males & 1.94 & $1.25-3.02$ & \\
\hline $\begin{array}{l}\text { Chhang consumption in units } \\
\text { of ethanol per day* }\end{array}$ & & & 0.10 \\
\hline$<5$ & 1.00 & - & - \\
\hline $5-15$ & 0.70 & $0.44-1.13$ & 0.14 \\
\hline $15-30$ & 0.76 & $0.45-1.29$ & 0.30 \\
\hline$\geq 30$ & 0.35 & $0.14-0.87$ & 0.03 \\
\hline $\begin{array}{l}\text { Rakshi consumption in units } \\
\text { of ethanol per day* }\end{array}$ & & & $<0.001$ \\
\hline$<5$ & 1.00 & - & - \\
\hline $5-15$ & 0.61 & $0.36-1.02$ & 0.06 \\
\hline $15-30$ & 1.81 & $1.08-3.04$ & 0.03 \\
\hline$\geq 30$ & 2.99 & $1.37-6.52$ & 0.006 \\
\hline $\begin{array}{l}\text { Tongba consumption in units } \\
\text { of ethanol per day** }\end{array}$ & & & 0.01 \\
\hline$<3$ & 1.00 & - & \\
\hline$\geq 3$ & 2.91 & $1.24-6.80$ & \\
\hline $\begin{array}{l}\text { Beer consumption in units } \\
\text { of ethanol per day** }\end{array}$ & & & 0.02 \\
\hline$<3$ & 1.00 & - & \\
\hline$\geq 3$ & 2.27 & $1.16-4.44$ & \\
\hline $\begin{array}{l}\text { Wine consumption in units } \\
\text { of ethanol per day }\end{array}$ & 1.02 & $0.92-1.13$ & 0.75 \\
\hline $\begin{array}{l}\text { Whisky consumption in units } \\
\text { of ethanol per day }\end{array}$ & 1.25 & $0.93-1.69$ & 0.14 \\
\hline Total units of ethanol per day* & & & 0.17 \\
\hline$<10$ & 1.00 & - & - \\
\hline $10-15$ & 1.07 & $0.58-1.98$ & 0.83 \\
\hline $15-26$ & 1.65 & $0.94-2.87$ & 0.08 \\
\hline$>26$ & 1.61 & $0.92-2.83$ & 0.10 \\
\hline
\end{tabular}

Notes: *Category cutoffs based on the quartiles of distribution of those variables; **ategory cutoffs based on the median units.

Abbreviations: $\mathrm{OR}$, odds ratio; $\mathrm{Cl}$, confidence interval.

uation of drinking patterns and types of alcohol used showed a significant increase in the risk of developing ALD with the consumption of rakshi and tongba, after adjusting for total units consumed. Interestingly, there was no increased risk of ALD with the consumption of chhang, though the percentage of alcohol in chhang is more than that in tongba. We admit that the alcohol concentration in chhang may vary according to the freshness of the beverage and the fermentation process. However, we took great care to collect three samples of chhang and to measure the alcohol content. In addition, 39 of the exclusive 50 chhang drinkers were alcohol dependent, which suggests that the chhang used by our patients did contain a significant amount of alcohol, but that it also had limited toxicity. It may be speculated that the limited toxicity of chhang in our population may be due to the absence of cofactors suspected to potentiate liver disease, such as
Table 3 Factors associated with the likelihood of having chronic liver disease (multivariate analysis)

\begin{tabular}{|c|c|c|c|}
\hline Variables & OR & $95 \% \mathrm{Cl}$ & $P$-value \\
\hline Sex & & & 0.02 \\
\hline Females & 1.00 & - & \\
\hline Males & 1.81 & I.I2-2.94 & \\
\hline Age & & & 0.10 \\
\hline$<45$ years & 1.00 & - & - \\
\hline$\geq 45-53$ years & 1.26 & $0.68-2.33$ & 0.47 \\
\hline$\geq 54-63$ years & 1.92 & $1.06-3.49$ & 0.03 \\
\hline$>63$ years & 1.02 & $0.55-1.88$ & 0.95 \\
\hline $\begin{array}{l}\text { Chhang consumption in units } \\
\text { of ethanol per day }\end{array}$ & & & 0.35 \\
\hline$<5$ & 1.00 & - & - \\
\hline $5-15$ & 1.07 & $0.62-1.85$ & 0.80 \\
\hline $16-30$ & 1.07 & $0.60-1.94$ & $0.8 I$ \\
\hline$>30$ & 0.44 & $0.17-1.16$ & 0.10 \\
\hline $\begin{array}{l}\text { Rakshi consumption in units } \\
\text { of ethanol per day }\end{array}$ & & & 0.005 \\
\hline$<5$ & 1.00 & - & - \\
\hline $5-15$ & 0.64 & $0.37-1.10$ & 0.11 \\
\hline $16-30$ & 1.63 & $0.91-2.93$ & 0.10 \\
\hline$>30$ & 2.53 & $1.07-6.01$ & 0.04 \\
\hline $\begin{array}{l}\text { Tongba consumption in units } \\
\text { of ethanol per day }\end{array}$ & & & 0.02 \\
\hline$<3$ & 1.00 & - & \\
\hline$\geq 3$ & 3.02 & I.22-7.50 & \\
\hline $\begin{array}{l}\text { Total units of other alcohols } \\
\text { consumed per day }\end{array}$ & & & 0.13 \\
\hline$<5$ & 1.00 & - & - \\
\hline $5-10$ & 1.45 & $0.62-3.38$ & 0.40 \\
\hline$>10$ & 2.98 & $0.97-9.11$ & 0.06 \\
\hline
\end{tabular}

Notes: Hosmer-Lemeshow test, $P=0.49$ (goodness of fit); area under the curve, 69.6\%; $95 \% \mathrm{Cl}: 64.3 \%-74.9 \%$ (predictive value of the model).

Abbreviations: $\mathrm{OR}$, odds ratio; $\mathrm{Cl}$, confidence interval.

nutritional/antioxidant deficiency, metabolic syndrome, and so on. However, we did not identify any social, professional, or economic differences between chhang drinkers, on the one hand, and users of other alcoholic beverages, on the other. Obesity and poor nutrition may contribute variably to the development of ALD. Indeed, in a large study of hospitalized patients with varying severity of ALD, ${ }^{16}$ malnutrition (especially the type caused by deficient protein and calories) was closely associated (although not necessarily causal) with the severity of liver injury. All patients with clinical evidence for ALD (regardless of severity) exhibited some features of malnutrition. Obesity potentiates the severity of alcohol-induced liver damage. ${ }^{17}$ While alcohol is a major cause of liver cirrhosis, recent evidence suggests that excess body weight may also play a role. In our study, we found a significantly high body mass index (BMI) in patients with CLD, as compared to patients with no liver disease, though the mean BMI levels in both the groups were within normal 
limits. However, there was a linear increase in the risk for the development of CLD with increasing rakshi consumption, and a significant risk in patients consuming $\geq 30$ units per day. We do not know the cause of toxicity of rakshi. The toxicity of rakshi may be related to the manufacturing process, the fermentation process, and the additives used. It may also be possible that rakshi drinkers are more exposed to other known cofactors for liver disease than chhang drinkers, which were not recorded in this study.

There are conflicting data regarding the type of alcohol consumed and the risk for developing liver disease. Grønbaek et $\mathrm{al}^{18}$ found that the risk of developing cirrhosis in wine drinkers was less than $50 \%$ of the risk in nonwine drinkers for any given level of total alcohol intake, while beer and spirit drinking did not modify the relationship between total alcohol intake and the risk of developing cirrhosis. This may be because of the fact that a person who prefers beer is more likely to become a heavy or excessive drinker than a person who prefers wine. ${ }^{18}$ However, the data regarding a possible lower risk of liver injury in wine drinkers are conflicting. ${ }^{19,20}$ In a study performed in India, ALD occurred more commonly with the consumption of illicit liquor, despite its lower alcohol content. ${ }^{21}$ In a prospective study of 258 alcohol-abusing men, Sørensen et $\mathrm{al}^{22}$ did not find any relationship between preferred alcohol type and the subsequent incidence of cirrhosis. However, data regarding only the preference for beer or spirits, but not for wine, were available in that study. In yet another study, researchers found that when the alcohol intake is high, the risk for developing alcoholic cirrhosis is equal, irrespective of the type of alcoholic beverage. ${ }^{20}$ Conversely, Becker et al ${ }^{19}$ demonstrated a lower risk for alcohol-induced cirrhosis in wine drinkers. Free radical formation after alcohol intake and a reduced level of antioxidants has been implicated in the pathogenesis of alcohol-induced liver disease..$^{23,24}$ Nonalcoholic constituents of wine have antioxidant properties. ${ }^{25,26}$ Furthermore, an antioxidant effect of the nonalcoholic constituents of wine has most often been suggested to account for the beneficial effect of wine over other alcoholic beverages. ${ }^{27,28}$ Kerr et al ${ }^{29}$ also found beverage-specific associations with cirrhosis.

In Nepal, wine is consumed very rarely, mainly because it is expensive by local standards, and since locally brewed alcohol is available at much cheaper rates and it is also more widely available. Locally brewed alcoholic beverages frequently contain aliphatic alcohols as byproducts, and the amount of these contaminants in spirits varies considerably depending on the raw materials and production methods used. ${ }^{30}$ Consequently, it is plausible that the differences in alcohol consumption among countries may vary, not only in quantity, but also in quality. There is, however, no information on the composition of locally-produced alcohol in this region, and concerns about the potentially toxic effects of contaminants (such as aliphatic alcohols) may explain the results of our study, which showed a significant association between ALD and rakshi and tongba consumption, and no liver disease with the consumption of chhang. As liver biopsy was not performed in all cases, one could suspect a misclassification of ALD. However, in our study, the diagnosis of ALD was made either based on histological examination of the liver, or on the presence of several well-defined and widely accepted medical criteria when liver biopsy was not performed. For the control group, we used an inverse procedure, which excluded all the medical signs that were potentially associated with liver cirrhosis before the final classification (this was indicative of not having liver disease). Performing a liver biopsy in this group of patients was not possible for obvious ethical reasons. Altogether, the risk of an error in classification was thus extremely low.

\section{Conclusion}

The findings of this study provide a precise picture of drinking patterns that are profoundly influenced by cultural habits and the availability of homemade beverages. In addition, the increased risk of ALD in rakshi consumers compared to consumers of other alcoholic beverages (after adjusting for total units consumed) indicates the possibility of specific toxicity for some homemade alcoholic beverages. The absence of striking differences between our CLD patients and non-CLD patients with respect to the amount of alcohol consumed demonstrates that although alcohol consumption is a prerequisite for the development of ALD, other factors like type of alcoholic beverage consumed and excess body weight may be involved.

\section{Acknowledgment}

This research work titled "Alcoholic liver disease in Nepal: identifying homemade alcohol as a culprit" was presented as a poster at the World Congress of Internal Medicine 2014, held in Seoul, South Korea from October 24-28, 2014.

\section{Disclosure}

The authors report no conflicts of interest in this work.

\section{References}

1. Becker U, Deis A, Sørensen TI, et al. Prediction of risk of liver disease by alcohol intake, sex, and age: a prospective population study. Hepatology. 1996;23(5):1025-1029. 
2. Kamper-Jørgensen M, Grønbaek M, Tolstrup J, Becker U. Alcohol and cirrhosis: dose - response or threshold effect? J Hepatol. 2004;41(1): 25-30.

3. Mandayam S, Jamal MM, Morgan TR. Epidemiology of alcoholic liver disease. Semin Liver Dis. 2004;24(3):217-232.

4. Bellentani S, Saccoccio G, Costa G, et al. Drinking habits as cofactors of risk for alcohol induced liver damage. The Dionysos Study Group. Gut. 1997;41(6):845-850.

5. Day CP. Who gets alcoholic liver disease: nature or nurture? J R Coll Physicians Lond. 2000;34(6):557-562.

6. Becker U. Liver disease. Importance of gender and type of alcohol [abstract]. Alcohol Clin Exp Res. 1998;22(Suppl 1):139A.

7. Chou SP, Grant BF, Dawson DA. Alcoholic beverage preference and risks of alcohol-related medical consequences: a preliminary report from the National Longitudinal Alcohol Epidemiologic Survey. Alcohol Clin Exp Res. 1998;22(7):1450-1455.

8. Strubelt O, Deters M, Pentz R, Siegers CP, Younes M. The toxic and metabolic effects of 23 aliphatic alcohols in the isolated perfused rat liver. Toxicol Sci. 1999;49(1):133-142.

9. McKarns SC, Hansch C, Caldwell WS, Morgan WT, Moore SK, Doolittle DJ. Correlation between hydrophobicity of short-chain aliphatic alcohols and their ability to alter plasma membrane integrity. Fundam Appl Toxicol. 1997;36(1):62-70.

10. First MB, Gibbon M, Spitzer RL, Williams JBW. User Guide for the Structured Clinical Interview for DSM-IV-TR Axis I Disorders Research Version (SCID-I for DSM-IV-TR, February 2001 Revision). New York, NY: Biometrics Research; 2001.

11. Lelbach WK. Cirrhosis in the alcoholic and its relation to the volume of alcohol abuse. Ann NY Acad Sci. 1975;252:85-105.

12. McCullough AJ, O'Connor JF. Alcoholic liver disease: proposed recommendations for the American College of Gastroenterology. Am J Gastroenterol. 1998;93(11):2022-2036.

13. Bravo AA, Sheth SG, Chopra S. Liver biopsy. N Engl J Med. 2001; 344(7):495-500.

14. Deleuran T, Vilstrup H, Becker U, Jepsen P. Epidemiology of alcoholic liver disease in Denmark 2006-2011: a population-based study. Alcohol Alcohol. 2015;50(3):352-357.

15. Wang H, Ma L, Yin Q, Zhang X, Zhang C. Prevalence of alcoholic liver disease and its association with socioeconomic status in north-eastern China. Alcohol Clin Exp Res. 2014;38(4):1035-1041.

16. Mendenhall CL, Anderson S, Weesner RE, Goldberg SJ, Crolic KA. Protein-calorie malnutrition associated with alcoholic hepatitis. Veterans Administration Cooperative Study Group on Alcoholic Hepatitis. Am J Med. 1984;76(2):211-222.
17. Diehl AM. Obesity and alcoholic liver disease. Alcohol. 2004;34(1): 81-87.

18. Grønbaek M, Jensen MK, Johansen D, Sørensen TI, Becker U. Intake of beer, wine and spirits and risk of heavy drinking and alcoholic cirrhosis. Biol Res. 2004;37(2):195-200.

19. Becker U, Grønbaek M, Johansen D, Sørensen TI. Lower risk for alcoholinduced cirrhosis in wine drinkers. Hepatology. 2002;35(4):868-875.

20. Pelletier S, Vaucher E, Aider R, et al. Wine consumption is not associated with a decreased risk of alcoholic cirrhosis in heavy drinkers. Alcohol Alcohol. 2002;37(6):618-621.

21. Narawane NM, Bhatia S, Abraham P, Sanghani S, Sawant SS Consumption of 'country liquor' and its relation to alcoholic liver disease in Mumbai. J Assoc Physicians India. 1998;46(6):510-513.

22. Sørensen TI, Orholm M, Bentsen KD, Høybye G, Eghøje K, Christoffersen P. Prospective evaluation of alcohol abuse and alcoholic liver injury in men as predictors of development of cirrhosis. Lancet. 1984;2(8397):241-244.

23. Reinke LA, Moore DR, McCay PB. Free radical formation in livers of rats treated acutely and chronically with alcohol. Alcohol Clin Exp Res. 1997;21(4):642-646.

24. Nordmann R. Alcohol and antioxidant systems. Alcohol Alcohol. 1994;29(5):513-522.

25. Frankel EN, Kanner J, German JB, Parks E, Kinsella JE. Inhibition of oxidation of human low-density lipoprotein by phenolic substances in red wine. Lancet. 1993;341(8843):454-457.

26. Kawada N, Seki S, Inoue M, Kuroki T. Effect of antioxidants, resveratrol, quercetin, and $\mathrm{N}$-acetylcysteine, on the functions of cultured rat hepatic stellate cells and Kupffer cells. Hepatology. 1998;27(5):1265-1274.

27. Howard A, Chopra M, Thurnham D, Strain J, Fuhrman B, Aviram M. Red wine consumption and inhibition of LDL oxidation: what are the important components? Med Hypotheses. 2002;59(1):101-104.

28. Folts JD. Potential health benefits from the flavonoids in grape products on vascular disease. Adv Exp Med Biol. 2002;505:95-111.

29. Kerr WC, Fillmore KM, Marvy P. Beverage-specific alcohol consumption and cirrhosis mortality in a group of English-speaking beer-drinking countries. Addiction. 2000;95(3):339-346.

30. Leon DA, Chenet L, Shkolnikov VM, et al. Huge variation in Russian mortality rates 1984-94: artefact, alcohol, or what? Lancet. 1997;350(9075):383-388.
Clinical and Experimental Gastroenterology

\section{Publish your work in this journal}

Clinical and Experimental Gastroenterology is an international, peerreviewed, open access journal, publishing all aspects of gastroenterology in the clinic and laboratory, including: Pathology, pathophysiology of gastrointestinal disease; Investigation and treatment of gastointestinal disease; Pharmacology of drugs used in the alimentary tract;

\section{Dovepress}

Immunology/genetics/genomics related to gastrointestinal disease. This journal is indexed on CAS. The manuscript management system is completely online and includes a very quick and fair peer-review system. Visit http://www.dovepress.com/testimonials.php to read real quotes from published authors. 